\title{
TYREOLIBERIN (TRH) - THE REGULATORY NEUROPEPTIDE OF CNS HOMEOSTASIS
}

\author{
Danuta JANTAS \\ Department of Experimental Neuroendocrinology, Institute of Pharmacology, \\ Polish Academy of Sciences
}

DOI: $10.2478 / \mathrm{v} 10052-010-0008-4$

Summary: The physiological role of thyreoliberin (TRH) is the preservation of homeostasis within four systems (i) the hypothalamic-hypophsysiotropic neuroendocrine system, (ii) the brain stem/midbrain/spinal cord system, (iii) the limbic/cortical system, and (iv) the chronobiological system. Thus TRH, via various cellular mechanisms, regulates a wide range of biological processes (arousal, sleep, learning, locomotive activity, mood) and possesses the potential for unique and widespread applications for treatment of human illnesses. Since the therapeutic potential of TRH is limited by its pharmacological profile (enzymatic instability, short half-life, undesirable effects), several synthetic analogues of TRH were constructed and studied in mono- or adjunct therapy of central nervous system (CNS) disturbances. The present article summarizes the current state of understanding of the physiological role of TRH and describes its putative role in clinical indications in CNS maladies with a focus on the action of TRH analogues.

Key words: thyreoliberin, metabolism, neuromodulator, nootropic factor, analepsy, antidepressant, neuroprotection

\section{INTRODUCTION}

TRH (thyreoliberin, thyrotropin releasing hormone) was one of the first described factors released from the hypothalamus which acts as a neurohormone $[4,7]$. It is a tripeptide with a molecular weight of $359.5 \mathrm{Da}$, which is known mainly for its physiological role as a regulator of the hypothalamus-pituitarythyroid (HPT) axis. In addition to its stimulatory action at the level of the pituitary, promoting the release of thyreotropin ( $\mathrm{TSH}$, thyroid stimulating hormone) and prolactin, TRH also has a profound action on the central and peripheral nervous systems. Wide distribution of TRH and its receptors in the central nervous system 
(CNS) has provided the basis for investigating its role in the physiology and pathology of the CNS, which has lead to the description of its potential clinical applications (Table 1). Since TRH as a drug has many limitations, e.g. short halflife, low bioavailability, and peripheral side effects, a number of its synthetic analogues were constructed and investigated as potential drugs in the treatment of CNS maladies.

This review article summarizes the current state of knowledge on the role of TRH in the regulation of several processes in the CNS, with an emphasis on its homeostatic properties. It aims to describe the potential clinical value of synthetic analogues of TRH in treatment of CNS disorders.

TABLE 1. Potential clinical implications for TRH and its analogues.

\begin{tabular}{|c|}
\hline POTENTIAL CLINICAL IMPLICATIONS FOR TRH AND ITS ANALOGUES \\
\hline Depression \\
\hline Chronic fatigue syndromes \\
\hline Narcolepsy, neurasthenia, lethargy \\
\hline Sedation secondary to drugs, chemo- or radiation therapy \\
\hline Sedative intoxication/Respiratory distress \\
\hline Recovery from general anesthesia \\
\hline Attention deficit/hyperactive disorder (ADHD) \\
\hline Disturbances of circadian rhythm (e.g. jet lag) \\
\hline Bipolar affective disorder* \\
\hline Anxiety disorders * \\
\hline Alzheimer's disease and other dementias with cognition deficits * \\
\hline Seizure disorders * \\
\hline Motor neuron disorders * \\
\hline may be particularly effective as adjunctive therapy \\
\hline
\end{tabular}

\section{TRH - BIOSYNTHESIS, METABOLISM, DISTRIBUTION AND INTRACELLULAR MECHANISMS OF ACTION}

TRH (L-pyroglutamyl-L-histydyl-prolineamide; pGlu-His-ProNH $\mathrm{N}_{2}$ ) is synthesized mainly in the paraventricular nuclei of the hypothalamus (PVN) and secreted into hypothalamo-hypophyseal portal vessels. It functions in the anterior pituitary by stimulating secretory cells (thyrotropes - TSH releasing cells, mammotropes - prolactin releasing cells) to produce thyreotropin and prolactin $[11,23]$. TRH can be synthesized locally in some regions of the CNS (cerebral 
cortex, hippocampus, spinal cord), as well as in the periphery (pancreatic beta cells, testes) where it is involved in the local regulation of several cellular processes [11, 23]. The gene encoding TRH contains three exons separated by two non-coding introns. The biosynthesis of TRH is a five-step process, beginning in the nucleus with the transcription of DNA from the TRH gene to the TRH mRNA, and the production of the prepro-TRH mRNA form, which encodes for five or six mature TRHs in the murine and human mRNA, respectively. Transcription is followed by translation to the pro-TRH peptide (Lys-Arg-Gln-His-Pro-Gly-Lys-Arg) on the ribosome $[11,23]$. The next steps are the post-translational processing of pro-TRH, beginning with the cleavage of pairs of Lys-Arg residues by the enzymatic action of carboxypeptitase E to generate the intermediate Gln-His-Pro-Gly product. This peptide is subsequently amidated at the proline residue by a peptidyl-glicyne $\alpha$ amidating monooxygenase. The final step of TRH biosynthesis is the Gln cyclization to the pGln form by glutaminyl cyclase and the generation of active tripeptide pGlu-His-ProNH ${ }_{2}$. Interestingly, the cleavage of pro-TRH peptide leads not only to production of TRH but also to the generation of other bioactive peptides (TRH-like peptides), although their biological role has not yet been fully identified [11]. It is hypothesized that the post-translational modifications of pro-TRH occurs mainly in neuronal cell bodies because to date, the presence of pro-TRH in neuronal processing (dendrites and axons) has not yet been shown [11]. The biosynthesis of TRH in PVN is strictly regulated by hormones secreted by the pituitary (TSH) and thyroids (triiodothyroine and tyroxine) via a system of negative feedback loops [11]. Moreover, the function of TRH-ergic neurons of PVN can be regulated by other neuroendocrine substances (e.g. vasopressin, oxytocin, glucocorticoids, leptin, galanin, somatostatin, neurotensin), and several neurotransmitters and neuromodulators (e.g. norepinephrine, adrenaline, dopamine, neuropeptide Y, opioids, glutamate, GABA) [9-11, 53]. The TRH half-life in plasma is rather short and ranges from 2 to 6 min in both animals and humans [34]. The rapid degradation of TRH after release from cells is the main factor limiting its potential use as a therapeutic agent. Specific proteolytic enzymes which act on TRH can be found in many tissues, including brain, spinal cord, pituitary, liver, kidney, pancreas, adrenal glands and blood [11,34]. Tyreoliberinases (histydylproline imidopeptidases) are mainly responsible for TRH degradation in blood, while pyroglutamyl endopeptidases (PPI and PPII) and propyl endopeptidase act mainly in the CNS. A result of the action of TRH metabolizing enzymes is the generation of physiologically active substances like stable cyclized metabolite CHP (histydyl-proline-diketopiperizine) and deamidated free acid, TRH-OH [11, 34]. 


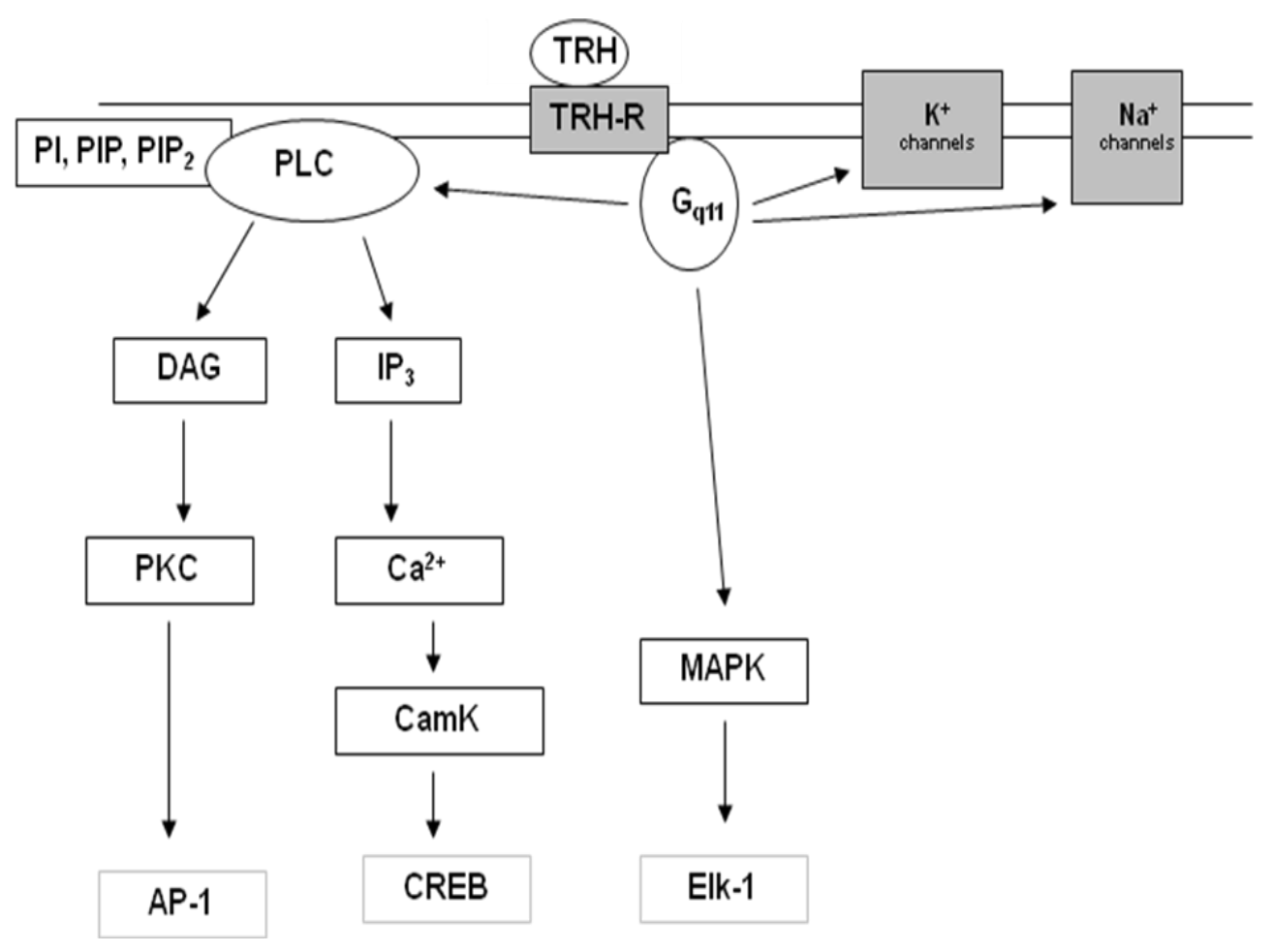

FIGURE 1. Intracellular mechanisms of TRH action

TRH appears to initiate its biological activity by binding with high affinity to the cell membrane of thyrotropin releasing hormone receptors (TRH-R) (Fig. 1). THR-R belongs to the family of matabotropic receptors, which have 7 transmembrane domains, and is coupled to the $\mathrm{G}_{\mathrm{q} 11}$ protein. Activation of this protein leads to the stimulation of a intracellular secondary transducer system connected with the phospolipase C (PLC) pathway [13, 46]. PLC hydrolyzes the phosphoinositols of the cell membrane (phosphatydyl-inositol - PI, phosphatydylinositol-3-phosphate - PIP, phosphatydyl-inositol-4,5-diphosphate - $\mathrm{PIP}_{2}$ ) and generates secondary messengers such as diacyloglicerol (DAG) and inositol$(1,4,5)$-triphosphate $\left(\mathrm{IP}_{3}\right)$. Subsequently, DAG can stimulate protein kinase C activity (PKC) which in turn, can activate some transcriptions factors (e.g. AP-1), or modulate the action of other intracellular proteins via phosphorylation. $\mathrm{IP}_{3}$ bound to its receptor localized on the endoplasmatic reticulum (ER), leads to calcium outflow and an increase in the cytoplasmic $\mathrm{Ca}^{2+}$ level. Released $\mathrm{Ca}^{2+}$ binds to calmodulin and these complexes activate $\mathrm{Ca}^{2+} / \mathrm{calmodulin}$-dependent protein kinases (CaMK) which can influence the activity of transcription factors (e.g. CREB - cAMP-response binding protein). It was shown that TRH can also act via its receptors and stimulate the intracellular MAPK (mitogen-activated protein 
kinases) pathway, which activates other transcription factors such as Elk-1. After ligand binding, TRH-R like other metabotropic receptors, are quickly desensitized and internalized [46]. There is widespread distribution of TRH receptors in the brain with the highest occurrence in the limbic regions (hypothalamus, amygdala) and the lowest in the brain stem and cerebellum [11,34].

The first cloned TRH receptor was TRH-R1, which was discovered in rodents and later in humans $[11,34]$. There is relatively high DNA $(90 \%)$ and amino acid (95\%) homology in the TRH-R1 gene and protein among different animal species. The second described receptor for tyreoliberin was TRH-R2, which was first discovered in rats and later in other animals, but to date its existence in humans has not been confirmed $[34,46]$. There is approximately $50 \%$ homology between TRH-R1 and TRH-R2 receptors at the amino acid level within an animal species. The two types of TRH-R differ in their localization within the brain, with concentrated expression of TRH-R1 in neuroendocrine regions and autonomic nervous system and TRH-R2 dominance in cerebral cortex, midbrain, thalamus and subthalamus [34]. There are also regions in the brain, such as the brain stem, where both types of TRH receptors colocalize. Recently, a third type of TRH-R was described (TRH-R3) in Xenopus laevis [3], but its existence in other animal species has not yet been reported. Thyreoliberin possesses similar affinity to TRH-R1 and TRH-R2 and after binding to the receptor, activates the intracellular signaling pathway, connected with the $\mathrm{G}_{\mathrm{q} 11}$ protein, to induce a similar maximal signaling level [34]. The only difference between the two types of TRH receptors is the level of basal signaling activity, with TRH-R2 being higher than TRH-R1. This could influence the rate of receptor desensitization and internalization and subsequently, could have an impact on downstream secondary intracellular signaling. TRH evokes its biological effect not only via secondary messenger systems, but TRH receptor activated $\mathrm{G}$ proteins can also directly inhibit potassium $\left(\mathrm{K}^{+}\right)$or sodium $\left(\mathrm{Na}^{+}\right)$channels. The above mechanism could explain some central effects of TRH, such as nootropic, and anti-epileptic activity [55]. Finally, it was shown that in addition to the specific action of TRH on its own receptors (TRH-R), it is also able to bind to others, such as the melanocortin $\mathrm{MC}_{1}$ receptor, which is a promising target for the development of anti-inflammatory and immuno-modulatory drugs $[45,52]$.

\section{STIMULATORY EFFECTS OF TRH IN THE CNS AND ITS POTENTIAL CLINICAL IMPLICATIONS}

TRH plays a key role in the HPT axis in regulating the function of peripheral endocrine organs, mainly the thyroid. Its endocrine action is profoundly connected with regulation of metabolism at the whole body level as well as single cells [23]. Approximately $2 / 3$ of the body's TRH content is localized away from 
the HPT axis, and is concomitant with the widespread distribution of TRH receptors throughout the brain, thus potentially resulting in a wide spectrum of central stimulatory effects $[23,34]$. TRH is recognized as a neurotransmitter, which, considering its specific receptors in the CNS could evoke different effects within the brain. It can also act as a neuromodulator, which regulates the action of several neuronal pathways like the dopaminergic, serotoninergic, acetylcholinergic and opioid systems.

TRH invokes an ergotropic action in the CNS (mobilizing organisms to work as a source of energy) and influences body arousal, sleep, cognition, locomotion and mood [31]. Recently, the role of TRH as the CNS homeostatic regulator has been described [21]. The preservation of homeostasis in the brain is a result of the action of TRH on four systems: the hypothalamic-hypophsysiotropic neuroendocrine system, the brain stem/midbrain/spinal cord system, the limbic/cortical system and the chronobiological system.

A very important role of TRH at the level of midbrain and brain stem is in the regulation of water and food intake, as well as an involvement in thermoregulation [23]. As TRH inhibits food and water intake, it was considered for potential use in the treatment of obesity. The anorexiogenic mechanisms of action of TRH are complex and the TRH expression is stimulated in part by other anorexiogenic peripheral (leptin) and central (proopiomelanocortin - POMC; CART - cocaine and amphetamine regulated transcripts; $\alpha$-melanocortin - $\alpha$-MSH) peptides, but is also inhibited by the oryxogenic peptide, neuropeptide Y [23, 48]. Another biological role of TRH is in maintaining homeostasis in thermoregulation centers, which are susceptible to cold and the induction of hyperthermia. The thermoregulatory feature of TRH is important not only from a biological point of view (the role TRH in hibernation), but could also be used in a clinical setting for the restoration of body temperature after treatment with certain drugs which can cause hypothermia (e.g. barbiturates, chlorpromazine, alcohol, morphine, neurotensin) [34].

TRH peptide and its receptors are expressed in the SCN (hypothalamic suprachiasmatic nuclei) - a main region of chronobiological system [21,34], and are involved in modulation of circadian rhythms. TRH has been clinically tested in treatment of some dysfunction of circadian rhythms, such as narcolepsy, jet lag or depression [34].

There is strong evidence concerning the antidepressant effects of TRH, which were intensively investigated late last century $[1,20,21,50]$. The initial clues that lead to studying TRH as a putative antidepressant were observations of common clinical manifestations of patients with depression and hypothyroidism. The first clinical trials with TRH showed promise, as the antidepressive effects were achieved in relatively short time (1 day), as compared to the time required for the clinical action of classical antidepressants (3-4 weeks) [21]. The beneficial effect of TRH was also shown in treatment of bipolar disorder. While the first clinical trials with TRH were promising, further studies gave inconsistent results, which could have been influenced by the biological instability of TRH or side 
effects evoked by this peptide. Interestingly, recently published data point to the involvement of TRH in the therapeutic action of some drugs used in treatment of affective disorders. It was shown that TRH and TRH-R expression could be regulated by some antidepressants (escitalopram) and mood stabilizers (valproate, lithium salts) [38, 42, 43].

Other strong evidence for the connection between TRH and mood regulation has been found in TRH-R knock-out animals. TRH-R1 knock-out mice showed central dysfunction of HPT axis, mild hyperglycemia and only slight changes in growth, body weight and food intake. In these animals, an increased level of depressive and anxiogenic behavior was observed [56]. In contrast, in TRH-R2 knock-outs, neither the function of the HPT axis, metabolism of glucose, development nor growth were disturbed when compared to wild type mice. Interestingly, in female but not male TRH-R2 knock-out mice, the elevated depressive and attenuated anxiogenic behaviors were seen [47]. The above mentioned studies could provide a rationale for the potential use of TRH-R knockouts as an animal model for identifying potential drugs with antidepressive and/or anxiolytic action. As shown recently, the anxiolytic effects of TRH are mainly connected with action of this peptide on neurons located in amygdala [23].

Another interesting action of TRH is in the modulation of seizures. It has been shown that expression of TRH and its receptors is increased in the brain regions which were activated during seizure episode. On the other hand, exogenously administrated TRH was protective in limbic regions which were affected by drug-induced seizures in experimental animals [24-26, 30]. These data point to the potential for the use of TRH as a sole or adjuvant anticonvulsant drug [21].

Among the central effects of TRH, is its analeptic action. Peripheral administration of high doses of TRH, or lower doses injected directly into the brain evokes a 50\% reduction in pentobarbital-induced sleeping time in different animal species [34].

The analeptic properties of TRH are mainly due to its influence on the cholinergic system. This could potentially be used clinically to aid recovery after anesthesia, in consciousness disturbances after brain and spinal cord trauma, to antagonize sedation evoked by other factors (e.g. chemotherapy, radiotherapy, intoxication) [21]. The second action of TRH connected with stimulation of the cholinergic system is its beneficial influence on learning and memory processes. This is supported by observations made post mortem in Alzheimer's disease (AD) patients, where a decrease in TRH expression was found when compared to agematched healthy subjects [32]. On the other hand, the positive reinforcement of learning and memory processes after TRH administration in AD patients [33], has provided the rationale for testing TRH as a treatment of various type of dementias. However in humans, only slight improvements in cognition and memory were noticed in $\mathrm{AD}$ and alcohol-induced dementia [34]. 
As TRH is stimulatory for dopaminergic neurons and possesses some neuroprotective features, it was investigated as a treatment for Parkinson's disease [34]. The dopaminemimetic action of TRH is also associated with its influence on locomotor activity. Intracerebral and peripheral administration of TRH, has a similar effect as that of cocaine, increasing dopamine and serotonin release in rat nucleus accumbens and striatum, which is connected with the animal's elevated locomotor activity. Interestingly, the administration of TRH before cocaine, blocks the locomotor activity induced by the latter drug. Similar observations were made for morphine-induced place preference, where TRH was able to block the effect of morphine in this test, however was inactive when administrated alone [34].

All the above mentioned observations in this section describing the central effects of TRH, support the role of TRH as a CNS homeostatic regulator. Its action could be further characterized by two features of TRH, its analeptic and antiepileptic action. TRH is analeptic only when the subject is under sedation (for example after anesthetic drugs) and shows an anti-epileptic action only when the subject is threatened by seizures [34].

Apart from in the CNS, TRH also displays a significant physiological role in the peripheral nervous system. It stimulates motor neurons, and thus could be important in the treatment of motor neuron diseases. Some improvements, after treatment with TRH, were seen in patients with ALS (amyotrophic lateral sclerosis) and spinocerebellar degeneration [6, 21, 34]. TRH could elevate the activity of the sympathetic and parasympathetic nervous system, but these effects are dosedependent. This action is manifested by an increase in gastric acid secretions, elevated blood pressure and heart rate, and a (dose related) increase in the respiratory rate [34]. An interesting role of TRH, which has been extensively studied recently, is its influence on proper development and function of the pancreas, which in turn, is connected with regulation of glucose metabolism [54]. On one hand, the peripheral action of TRH could provide the rationale for use of this peptide in the treatment some peripheral disorders (e.g. cardiovascular diseases, diabetes). On the other hand, all above mentioned peripheral actions of TRH are undesired when considering TRH as a drug for treatment of CNS maladies.

There is an interesting group of endogenous peptides with a chemical structure similar to TRH, called TRH-like peptides, which are built according the scheme pGlu-X-ProNH2, where X can be any amino acid residue [34]. High concentrations of these peptides were found in the limbic regions of the brain, which could be connected with their influence on mood regulation. Substances from this family showed neuroprotective, antidepressant, euphoric and analeptic activities. Their biological action is not connected with TRH receptors (TRH-R1 and TRH-R2), but they can regulate several neuronal pathways in order to maintain body homeostasis, and appear to be a good target for the development new CNS active drugs [34]. 


\section{SYNTETHIC ANALOGUES OF TRH}

Enzymatic instability, low bioavailability after peripheral administration, and undesirable side-effects (hormonal and peripheral) of the naturally occurring form of TRH, were grounds for the development several synthetic analogues of TRH [34].

The first generation of TRH analogues was a result of specific single or dual substitution of particular amino acid residues in the TRH structure. These modifications gave substances which were resistant to degradation by TRH metabolizing enzymes, and possessed higher CNS activity, while having a lower influence on hormonal function.

Several promising analogues were created by the replacement of a $\mathrm{N}$ terminal pGlu residue. An example of this substitution is an orally active peptide, TA-0910 (taltirelin, Ceredist), which was patented by Mitsubishi Tanabe Pharma Corp as a neuroprotective drug, and since 2000, has been used in Japan to treat spinocerebellar degeneration. Taltirelin is active at concentrations of 100 times less, and for 8 times longer than the parent TRH peptide. Another interesting analogue from group of $\mathrm{N}$-terminal pGlu residue substitutions is montirelin (CG3703, NS3). This can act on TRH receptors and increase acetylcholine release. This analogue was patented by Grunenthal (Germany) as a potential drug for treatment of $\mathrm{AD}$, hypertension, for recovery from anesthesia and coma. A wide range of experimental studies performed in late last century, showed beneficial effects of montirelin on the inhibition of seizures, in recovery from anesthesia, and antagonizing the loss of consciousness after head trauma. Montirelin is effective in doses 10 times lower than TRH and is active for longer time. Additionally antidepressive and nootropic features of montirelin were showed in several animal studies.

Another synthetic peptide created by modification of pGlu residue was azetirelin (YM-14673), which was 10-100 times more potent than TRH in mice, and produced 8-36 times longer lasting analeptic activity and reversal of reserpine induced hypothermia. It was documented in the third phase of clinical trials that azetirelin could act as an anticonvulsant and cognition enhancer. Additionally, in animal models of ischemia its neuroprotective features were also demonstrated. However, clinical use was stopped due to its low bioavailability after oral administration and lack of lipophilicity.

There is also another group of analogues, which consist of peptides in which a middle peptide residue (L-His) is modified. By specific substitution of this residue, it was possible to create analogues with higher or lower hormonal and peripheral activity. Thus, these peptides could be beneficial for the treatment of HPT axis dysfunctions or in treatment of cardiovascular disorders. By replacement of L-His residue with pyridinum moieties, it was possible to obtain peptides with higher CNS activities, which were then tested as potential nootropic and anti- 
epileptic drugs. Specific modification of the L-His residue allowed the development of agents which are more selective to TRH-R2 than TRH-R1 and as a result they were devoid of hormonal activity.

TRH analogues developed as potential CNS drugs by dual substitutions in pGlu and L-His residues have shown great promise. In this way, the analogue RGH-2202 (posatirelin) was created, which was patented by Gedeon Richter (Hungary) as a putative neuroprotective drug. It showed nootropic and antiepileptic action, and improved learning and memory in experimental and clinical studies. Additionally, it has been shown to be 5 times more centrally active, and has only a slight influence on hormonal activity as compared to TRH. Its clinical development was stopped however due to its strong anorexiogenic and hypothermic action. Moreover, inconsistent data from clinical studies also added to its failure as a potential drug. However, new analogues with dual modification in the pGlu and L-His residues are still under development and are being tested as putative CNS active drugs [27].

The other group of TRH analogues was obtained by dual substitution of pGlu and L-ProNH2 residues. These analogues are also characterized by their increased proteolytic resistance and increased central activity, but unfortunately are not devoid of hormonal activity [34].

Currently the new generation of TRH analogues is under development (second generation). These agents have been created with lower affinity and higher effectiveness with regard to the stimulation of TRH receptors, especially TRH-R2 [14]. At the same time there have been attempts to develop TRH mimetics, which will possess two features: high affinity to centrally located TRH receptors, and an ability to act as an inhibitor of pyroglutamyl endopeptidase II (PPII) [44]. However, these agents are still in their early stages of development as CNS active substances, and further studies will show their effectiveness as putative drugs.

Apart from TRH analogues, synthesized derivatives of a TRH metabolite, dipeptide CHP, have also been developed. It has been shown that cyclic derivatives of CHP are neuroprotective in both acute and slowly progressing models of neuronal cell injury, while being devoid of hormonal and analeptic activity [17, $18]$.

Apart from chemical modifications of the TRH structure, efforts have been made to search natural substances in plants or sea invertebrates, which show affinity to TRH receptors, especially TRH-R2. As a result of large screening studies, it was found that two active substances from the plant Corymbia peltata (corymbone A i corymbone $\mathrm{B}$ ) possess strong affinity to the TRH-R2 receptor [8]. These will undoubtedly be investigated in the near future for their potential use in the treatment of some CNS disorders. 


\section{TRH ANALOGUES AND NEUROPROTECTION}

The first observations that pointed to the neuroprotective capacity of TRH, were made in an animal model of spinal cord injury. After intravenous TRH administration lower neurological deficits were seen as compared to an animal that received only buffered saline after neuronal injury [15]. Further studies using animal models of seizures demonstrated increased expression of TRH and its receptors in the regions of injury. This suggested an adaptive endogenous response of the central nervous system for pathologically elevated neuronal activity. Exogenously administrated TRH diminished the level of neuronal cell loss which was induced by convulsion episodes in genetic and chemical animal models of seizures $[25,26,28,29,41]$. However, due to TRH enzymatic instability a high dose was necessary to achieve a biological effect, and this lead to strong, undesirable side effects (hormonal and peripheral). During the years of development of the various kinds of TRH analogues, it was found that in order to maintain the neuroprotective effects of TRH, it is crucial to conserve the $\mathrm{L}-\mathrm{ProNH}_{2}$ residue $[17,19]$. The neuroprotective effects of TRH and its analogues (tartelin, montirelin, RGH-2202), were demonstrated in animals models of traumatic brain and spinal cord injury, as well in ischemia $[2,5,16,36,39,40,51]$. Studies with cyclic derivates of the TRH metabolite CHP, showed their efficiency as an antiexcitotoxic, anti-necrotic and anti-apoptotic agent in neuronal cells [16-18, 49]. This group of agents deserves special attention, as these peptides do not evoke the classic undesirable effects characteristic of TRH and its first generation analogues (hormonal, peripheral, analeptic, hyperthermic).

The mechanisms of the neuroprotective action of TRH are only partially understood. During acute injury of neuronal tissue, TRH could influence on release of glutamate, GABA, acetylcholine, endogenous opioids or leukotriens and restore an energetic status of cells which was affected during injury [12, 17, 35, 37]. Recently there has been very interesting data released, that points to receptor independent, intracellular mechanisms of the TRH neuroprotective action. It was reported that the protective action of some derivates of the TRH metabolite, CHP could be connected with their ability to down-regulate the expression of genes which are induced during neuronal injury (e.g. calpains, cathepsins, aquaporins). CHP can also be associated with the up-regulation of endogenously protective genes like BDNF - brain derived neurotrophic factor, heat shock proteins - Hsp70 and HIF-1 - hypoxia induced factor 1 [18]. The widespread action of derivates of the TRH metabolite, CHP, provides the rationale for further studies of these compounds in relation to their potential use as neuroprotective drugs. 


\section{SUMMARY}

Potential clinical applications of TRH, which have attracted special attention, have arisen from its nonhormonal action via stimulatory (nootropic) effects in the CNS. However, the mechanism of this phenomenon is still not fully understood, as there has been a lack of evidence of specific antagonists of the TRH receptor, which have limited the mechanistic studies. Recently, new agents with antagonistic action on TRH-R have been created, but they are still in the early stages of development [34]. The detailed explanation of the mechanisms of central effects of TRH is complicated, as there are several targets regulated by this endogenous peptide. Nevertheless, experimental studies have shown the clinical benefit of some of the TRH analogues. Examples of these include Taltirelin, which is used in Japan in treatment of spinocerebellar degeneration, Montirelin, which is studied as putative analeptic drug after brain injuries, and RGH-2202, which is in the second phase of a clinical trial as a memory enhancer. The role of TRH as a homeostatic regulator has been recently outlined [21], providing a rationale for the further development of new synthetic analogues, which will be investigated as potential drugs for treatment of CNS disorders. A wide range of such analogues continue to be constructed and studied in various experimental designs.

\section{ACKNOWLEDGMENTS}

This work was supported by grant KBN no. 2PO5A15530

\section{REFERENCES}

[1] ALKEMADE A, UNMEHOPA UA, WIERSINGA WM, SWAAB DF, FLIERS E. Glucocorticoids decrease thyrotropin-releasing hormone messenger ribonucleic acid expression in the paraventricular nucleus of the human hypothalamus. J Clin Endocrinol Metab. 2005; 90: 323-327.

[2] BEHRMANN DL, BRESNAHAN JC, BEATTIE MS. Modeling of acute spinal cord injury in the rat: neuroprotection and enhanced recovery with methylprednisolone, U-74006F and YM-14673. Exp Neurol. 1994; 126: 61-75.

[3] BIDAUD I, LORY P, NICOLAS P, BULANT M, LADRAM A. Characterization and functional expression of cDNAs encoding thyrotropin-releasing hormone receptor from Xenopus laevis. Eur J Biochem. 2002; 269: 4566-4576.

[4] BOLER J, ENZMANN F, FOLKERS K, BOWSER CY, SCHALLY AV. The identity of chemical and hormonal properties of the thyrotropin releasing hormone and pyroglutamyl-histidyl-proline amide. Biochem Biophys Res Commun. 1969; 37: 705-710.

[5] BORLONGAN CV, STAHL CE, REDEI E, WANG Y. Prepro-thyrotropin-releasing hormone 178199 exerts partial protection against cerebral ischemia in adult rats. Neuroreport 1999; 10: 3501-3505.

[6] BROOKS BR. A summary of the current position of TRH in ALS therapy. Ann N Y Acad Sci. 1989; 553: 431-461. 
[7] BURGUS R, DUNN TF, DESIDERO D, GUILLEMIN R. Molecular structure of the hypothalamic hypophysiotropic TRF factor of ovine origin: mass spectrometry demonstration of the PCA-His-ProNH2 sequence. C R Acad Sci Hebd Seances Acad Sci D. 1969, 269; 1870-1873.

[8] CARROLL AR, LAMB J, MONI R, GUYMER GP, FORSTER PI, QUINN RJ Myrtucommulones FI, phloroglucinols with thyrotropin-releasing hormone receptor-2 binding affinity from the seeds of Corymbia scabrida. J Nat Prod. 2008; 71: 1564-1568.

[9] CHIAMOLERA MI, WONDISFORD FE. Minireview: Thyrotropin-releasing hormone and the thyroid hormone feedback mechanism. Endocrinology. 2009; 150: 1091-1096.

[10] CIOSEK J. Influence of thyroliberin on vasopressin and oxytocin release from the hypothalamoneurohypophysial system under in vivo and in vitro conditions. Postepy Hig Med Dosw. 2007; 61: 429-437.

[11] CIOSEK J. Thyrotropin-releasing hormone (TRH): the biosynthesis, distribution, receptors and metabolism. Endokrynologia Polska 2004; 55 (5): 608-615.

[12] DENG PY, PORTER JE, SHIN HS, LEI S. Thyrotropin-releasing hormone increases GABA release in rat hippocampus. J Physiol. 2006; 577: 497-511.

[13] ENGEL S, GERSHENGORN MC. Thyrotropin-releasing hormone and its receptors--a hypothesis for binding and receptor activation. Pharmacol Ther. 2007; 113: 410-419.

[14] ENGEL S, NEUMANN S, KAUR N, MONGA V, JAIN R, NORTHUP J, GERSHENGORN MC Low affinity analogs of thyrotropin-releasing hormone are super-agonists. J Biol Chem. 2006; 281: 13103-13109.

[15] FADEN AI, JACOBS TP, HOLADAY JW. Thyrotropin-releasing hormone improves neurologic recovery after spinal trauma in cats. N Engl J Med. 1981; 305: 1063-1067.

[16] FADEN AI, KNOBLACH SM, CERNAK I, FAN L, VINK R, ARALDI GL, FRICKE ST, ROTH BL, KOZIKOWSKI AP. Novel diketopiperazine enhances motor and cognitive recovery after traumatic brain injury in rats and shows neuroprotection in vitro and in vivo. J Cereb Blood Flow Metab. 2003; 23: 342-354.

[17] FADEN AI, KNOBLACH SM, MOVSESYAN VA, LEA PM, CERNAK I. Novel neuroprotective tripeptides and dipeptides. Ann N Y Acad Sci. 2005; 1053: 472-481.

[18] FADEN AI, MOVSESYAN VA, KNOBLACH SM, AHMED F, CERNAK I. Neuroprotective effects. of novel small peptides in vitro and after brain injury. Neuropharmacology 2005; 49: 410-424.

[19] FADEN AI, SACKSEN I, NOBLE LJ. Structure-activity relationships of TRH analogs in rat spinal cord injury. Brain Res. 1988; 448: 287-293

[20] FOLTYN W, NOWAKOWSKA-ZAJDEL E, DANIKIEWICZ A, BRODZIAK A. Hypothalamicpituitary-thyroid axis in depression. Psychiatr Pol. 2002; 36: 281-292.

[21] GARY KA, SEVARINO KA, YARBROUGH GG, PRANGE AJ Jr, WINOKUR A. The thyrotropinreleasing hormone (TRH) hypothesis of homeostatic regulation: implications for TRH-based therapeutics. J Pharmacol Exp Ther. 2003; 305: 410-416.

[22] GUTIERREZ-MARISCAL M, de GORTARI P, LOPEZ-RUBALCAVA C, MARTINEZ A, JOSEPHBRAVO P. Analysis of the anxiolytic-like effect of TRH and the response of amygdalar TRHergic neurons in anxiety. Psychoneuroendocrinology. 2008; 33: 198-213.

[23] HOLLENBERG AN. The role of the thyrotropin-releasing hormone (TRH) neuron as a metabolic sensor. Thyroid. 2008;18: 131-139.

[24] JAWORSKA-FEIL L, KAJTA M, BUDZISZEWSKA B, LESKIEWICZ M, LASOŃ W. Protective effects of TRH and its stable analogue, RGH-2202, on kainate-induced seizures and neurotoxicity in rodents. Epilepsy Res. 2001; 43: 67-73.

[25] JAWORSKA-FEIL, TURCHAN J, PRZEWŁOCKA B, BUDZISZEWSKA B, LEŚKIEWICZ M, LASOŃ W. Effects of pilocarpine- and kainate-induced seizures on thyrotropin-releasing hormone biosynthesis and receptors in the rat brain. J Neural Transm. 1999; 106: 395-407.

[26] JAWORSKA-FEIL, TURCHAN J, PRZEWLOCKA B, BUDZISZEWSKA B, LEŚKIEWICZ M, LASOŃ W. Effects of pentylenetetrazole-induced kindling on thyrotropin-releasing hormone biosynthesis and receptors in rat brain. Neuroscience 1999; 90: 695-704.

[27] KAUR N, MONGA V, LU X, GERSHENGORN MC, JAIN R. Modifications of the pyroglutamic acid and histidine residues in thyrotropin-releasing hormone (TRH) yield analogs with selectivity for TRH receptor type 2 over type 1. Bioorg Med Chem. 2007; 15: 433-443. 
[28] KREIDER MS, WOLFINGER BL, WINOKUR A. Systemic administration of kainic acid produces elevations in TRH in rat central nervous system. Regul Pept. 1990; 28: 83-93.

[29] KUBEK MJ, KNOBLACH SM, SHARIF NA, BURT DR, BUTERBAUGH GG, FUSON KS Thyrotropin-releasing hormone gene expression and receptors are differentially modified in limbic foci by seizures. Ann Neurol. 1993; 33: 70-76.

[30] LASON W. Endogenous anticonvulsant and neuroprotective agents. Przegl Lek. 2004, 61: 1263-1267.

[31] LECHAN RM, FEKETE C. The TRH neuron: a hypothalamic integrator of energy metabolism. Prog Brain Res. 2006;153: 209-235.

[32] LUO L, STOPA EG. Thyrotropin releasing hormone inhibits tau phosphorylation by dual signaling. pathways in hippocampal neurons. J Alzheimers Dis. 2004; 6: 527-536.

[33] LUO L, YANO N, MAO Q, JACKSON IM, STOPA EG. Thyrotropin releasing hormone (TRH) in the hippocampus of Alzheimer patients. J Alzheimers Dis. 2002; 4: 97-103.

[34] MONGA V, MEENA CL, KAUR N, JAIN R. Chemistry and biology of thyrotropin-releasing hormone (TRH) and its analogs. Curr Med Chem. 2008; 15: 2718-2733.

[35] NIE Y, SCHOEPP DD, KLAUNIG JE, YARD M, LAHIRI DK, KUBEK MJ. Thyrotropin-releasing hormone (protirelin) inhibits potassium-stimulated glutamate and aspartate release from hippocampal slices in vitro. Brain Res. 2005; 1054: 45-54.

[36] NODA Y, FURUKAWA K, KOHAYAKAWA H, OKA M. Effects of RGH-2202 on behavioral deficits after focal cerebral ischemia in rats. Pharmacol Biochem Behav. 1995; 52: 695-699.

[37] OKA M, ITOH Y, UKAI Y, YOSHIKUNI Y, KIMURA K. Protein kinases are involved in prolonged acetylcholine release from rat hippocampus induced by thyrotropin-releasing hormone analogue NS-3. J Neurochem. 1996; 66: 1889-1893.

[38] PEKARY AE, SATTIN A, MEYERHOFF JL, CHILINGAR M. Valproate modulates TRH receptor, TRH and TRH-like peptide levels in rat brain. Peptides. 2004; 25: 647-658.

[39] PRZEWŁOCKA B, LABUZ D, MIKA J, LIPKOWSKI A, van LUIJTELAAR G, COENEN A, LASON W. Protective effects of TRH and its analogues in chemical and genetic models of seizures Pol J Pharmacol. 1997; 49: 373-378.

[40] PUNIAK MA, FREEMAN GM, AGRESTA CA, van NEWKIRK L, BARONE CA, SALZMAN SK.

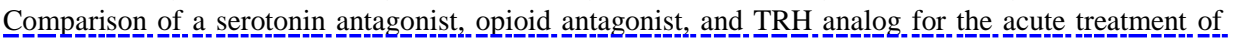
experimental spinal trauma. J Neurotrauma 1991; 8: 193-203.

[41] RAJPUT SK, KRISHNAMOORTHY S, PAWAR C, KAUR N, MONGA V, MEENA CL, JAIN R, SHARMA SS. Antiepileptic potential and behavioral profile of L-pGlu-(2-propyl)-L-His-L-ProNH2, a newer thyrotropin-releasing hormone analog. Epilepsy Behav. 2009; 14: 48-53.

[42] SATTIN A, PEKARY AE, BLOOD J. Escitalopram regulates expression of TRH and TRH-like peptides in rat brain and peripheral tissues. Neuroendocrinology. 2008; 88: 135-146.

[43] SATTIN A, SENANAYAKE SS, PEKARY AE. Lithium modulates expression of TRH receptors and TRH-related peptides in rat brain. Neuroscience. 2002; 115: 263-273.

[44] SCALABRINO GA, HOGAN N, O'BOYLE KM, SLATOR GR, GREGG DJ, FITCHETT CM, DRAPER SM, BENNETT GW, HINKLE PM, BAUER K, WILLIAMS CH, TIPTON KF, KELLY JA. Discovery of a dual action first-in-class peptide that mimics and enhances CNS-mediated actions of thyrotropin-releasing hormone. Neuropharmacology. 2007; 52: 1472-1481.

[45] SCHIOTH HB, PRUSIS P, MUCENIECE R, MUTULIS F, MUTULE I, WIKBERG JE. Thyrotropin releasing hormone (TRH) selectively binds and activates the melanocortin 1 receptor. Peptides. 1999; 20: 395-400.

[46] SUN Y, LU X, GERSHENGORN MC. Thyrotropin-releasing hormone receptors -z similarities and differences. J Mol Endocrinol. 2003; 30: 87-97.

[47] SUN Y, ZUPAN B, RAAKA BM, TOTH M, GERSHENGORN MC. TRH-Receptor-Type-2Deficient Mice are Euthyroid and Exhibit Increased Depression and Reduced Anxiety Phenotypes. Neuropsychopharmacology. 2008; Dec 10 [Epub ahead of print].

[48] VALASSI E, SCACCHI M, CAVAGNINI F. Neuroendocrine control of food intake. Nutr Metab Cardiovasc Dis. 2008; 18, 158-168.

[49] VERONESI MC, YARD M, JACKSON J, LAHIRI DK, KUBEK MJ. An analog of thyrotropinreleasing hormone (TRH) is neuroprotective against glutamate-induced toxicity in fetal rat hippocampal neurons in vitro. Brain Res. 2007; 1128: 79-85. 
[50] VETULANI J, NALEPA I. Antidepressants: past, present and future. Eur J Pharmacol. 2000; 405: 351-363.

[51] VINK R, McINTHOSH TK, FADEN AI. Treatment with the thyrotropin-releasing hormone analog CG3703 restores magnesium homeostasis following traumatic brain injury in rats. Brain Res. 1988; 460: $184-188$

[52] WIKBERG JE, MUCENIECE R, MANDRIKA I, PRUSIS P, LINDBLOM J, POST C, SKOTTNER A. New aspects on the melanocortins and their receptors. Pharmacol Res. 2000; 42: 393-420.

[53] WITTMANN G. Regulation of hypophysiotrophic corticotrophin-releasing hormone- and thyrotrophin-releasing hormone-synthesising neurones by brainstem catecholaminergic neurones. J Neuroendocrinol. 2008; 20: 952-960.

[54] YANO N, LUO L. Effect of thyrotropin releasing hormone (TRH) on gene expressions in rat pancreas: approach by microarray hybridization. JOP. 2004; 5: 193-204.

[55] YARBROUGH GG. Fundamental molecular mechanism of the CNS effects of TRH. Trends Pharmacol Sci. 2003; 24: 617-618.

[56] ZENG H, SCHIMPF BA, ROHDE AD, PAVLOVA MN, GRAGEROV A, BERGMANN JE Thyrotropin-releasing hormone receptor 1-deficient mice display increased depression and anxiety-like behavior. Mol Endocrinol. 2007; 21: 2795-2804

Corresponding author: Danuta Jantas

Department of Experimental Neuroendocrinology, Institute of Pharmacology, Polish Academy of Sciences

12 Smetna Street, 31-343 Krakow

phone: (012) 6623368

fax: (012) 6374500

e-mail: jantas@if-pan.krakow.pl 